\title{
EDITORIAL
}

\section{THE MNA IN 2013 - STILL GOING STRONGER AFTER ALMOST TWENTY YEARS}

\author{
J.M. BAUER
}

Geriatrisches Zentrum Oldenburg, Rahel-Straus-Straße 10, 24133 Oldenburg, Germany. bauer.juergen@klinikum-oldenburg.de

It has been in the early nineties when Bruno Vellas, Yves Guigoz and Philipp J. Gary developed the Mini Nutritional Assessment in a successful transatlantic research cooperation (1). It was their aim to provide geriatricians and all those that are professionally involved in the care of older individuals with a validated, but also practical tool for the nutritional screening of this at risk population. Since then hundreds of scientific papers have been published that included the MNA as a diagnostic standard for malnutrition in older persons. Even more important the MNA has gained wide acceptance as an officially recognised nutritional screening tool. For example after the 2011 Japan earthquake the MNA®- SF was used in evacuation centres to quickly and easily evaluate the nutritional status in vulnerable older adults. It may also be regarded as proof of the MNA's worldwide acceptance and significance that papers from four continents - Europe, America, Asia and Australia - have been included in this special issue of the JNHA.

The first section of this special issue includes several papers that provide us with new insight on the prevalence and the relevance of malnutrition in important geriatric subpopulations like those admitted to the emergency department (2), those attending dementia clincs (3), those affected by systolic heart failure (4), those with diabetes (5) and those beyond age 90 (6). For example, Roqué et al. describe a higher prevalence of malnutrition in dementia with Lewy bodies than in other forms of dementia (3). In addition their paper offers profound information on potential etiological factors for malnutrition in patients with dementia. The study by Sargento et al. documents the high prognostic relevance of malnutrition in a population of geriatric outpatients with systolic heart failure (4). Kuyumcu et al. describe for the first time the nutritional status of Turkish nursing home residents based on the MNA and document its relevance for the prediction of short-term mortality (7). Finally Jane Winter et al. observed that even among well-aging older adults in the community a relevant number will be at risk of malnutrition and that many of them will be found among those with BMI above $25 \mathrm{~kg} / \mathrm{m}^{2}(8)$.

Good things could sometimes still be made better. With regard to the MNA the desire to improve its practicability led to the development of the MNA Short Form, which in its original version from 2001 presented only two categories, "wellnourished" and "at risk" (9). At that time the use of the MNASF was still considered as a two-step procedure, which would include the completion of the full MNA in those classified at risk. With regard to the ongoing limitation of resources and with the clear aim to allow screening in a larger proportion of the older population a revised version of the MNA-SF was published in 2009 (10). The revised MNA-SF offers three results categories, which are identical to the original MNA. In addition if BMI is not available it can be substituted by calf circumference. The validity of this approach has recently been validated for a Spanish nursing home population by GarciaMeseguer et al (11).

In this special issue you find two papers that go even further with regard to MNA applicability. On the one hand it is Donini et al. that provide data on two new MNA versions that do without the BMI (12). Second Huhmann et al. tested a selfcompleted MNA which might offer an option to spread nutritional screening dramatically beyond the present boundaries induced mainly by scarce professional resources (13). However, other researchers have to verify whether this approach is in fact feasible. Diekmann et al. compared the MNA with other established nutritional screening tools like the NRS (Nutritional Risk Screening) and the MUST (Malnutrition Universal Screening Tool) with regard to applicability and prognostic value in the nursing home setting (14).

What we really care about in older persons is their functionality and their quality of life. Our main focus should not be the improvement of rather abstract nutritional parameters like weight, calf circumference or body composition. Those are definitely important from a scientific point of view but in most instances we will have to relate nutrition to function if we want to claim relevance. However, nutrition and functionality constitute a bidirectional relationship as one strongly influences the other. Therefore it has to be welcomed that three papers in this special issue focus on the links between the MNA and function. Frailty, mainly referred to as physical frailty and characterized by increased vulnerability as a consequence of multisystem dysregulation, is regarded as a highly relevant geriatric syndrome that is just about to enter clinical routine. Bollwein et al. analysed the relationship between MNA and frailty in community living older persons (15). Stange et al. (16) focus on the relationship between nutrition and functionality in a large population of nursing home residents, while Kiesswetter et al. illustrate this aspect in older adults receiving home care (17). Little information has been available in this regard before. 
The last section of this special issue includes two papers that may be seen as examples for thinking outside the box. Muzembo et al. point toward a potential relationship between malnutrition and peripheral arterial disease (18), while Charlton provides interesting information on the apperception of supplements among community living older individuals (19).

While I am confident that the diversity of the articles that have been included in this special issue will stimulate future research in the context of the MNA my true expectations go beyond that. All those who devote significant time and effort to the nutritional needs of the older population should strive to have the MNA routinely included in their evaluation, independent of the setting they are living in. However, we must not forget that the MNA has to be regarded only as a first step in the nutritional management of older persons, as it should be followed by individual assessment in those that have been categorized as malnourished.

Concerning public awareness of malnutrition in older persons some important steps forward have been realized in many countries in recent years, but we have to be cautious that we won't fall back again, especially under the strong economic pressure many of us face today. Complacency in this regard is therefore not indicated. However, the wide acceptance of the MNA among experts which is based on its usefulness and its reliability will help us to take a clear stand towards the nutritional needs of the older population and the use of MNA will thereby support the interests of our patients.

\section{References}

1. Guigoz Y, Vellas B, Garry PJ. Assessing the Nutritional Status of the Elderly: The Mini Nutritional Assessment as Part of the Geriatric Evaluation. Nutr Rev. 1996 Jan;54(1 Pt 2):S59-65.

2. Gentile S, Lacroix O, Durand AC, Cretel E, Alazia M, Sambuc R, Bonin-Guillaume S. Malnutrition: A Highly Predictive Risk Factor of Short-Term Mortality in Elderly Presenting to the Emergency Department. J Nutr Health Aging 2013;17(4):290-294

3. Roqué M, Salva A, Vellas B. Malnutrition in Community-Dwelling Adults With Dementia (NutriAlz Trial). J Nutr Health Aging 2013;17(4):295-299

4. Sargento L, Satendra M, Almeida I, Sousa C, Gomes S, Salazar F, Lousada N, Palma dos Reis R. Nutritional Status of Geriatric Outpatients with Systolic Heart Failure and Its Prognostic Value Regarding Death or Hospitalization, Biomarkers and
Quality of Life. J Nutr Health Aging 2013;17(4):300-304

5. Alfonso-Rosa RM, del Pozo-Cruz B, del Pozo-Cruz J, del Pozo-Cruz JT, B. Sañudo B. The Relationship between Nutritional Status, Functional Capacity, and HealthRelated Quality of Life in Older Adults with Type 2 Diabetes: A Pilot Explanatory Study. J Nutr Health Aging 2013;17(4):315-321

6. Vandewoude M, Van Gossum A. Nutritional Screening Strategy in Nonagenarians: The Value of the MNA-SF (Mini Nutritional Assessment Short Form) in NutriAction. J Nutr Health Aging 2013;17(4):310-314

7. Ulger Z, Halil M, Cankurtaran M, Yavuz BB, Yesil Y, Kuyumcu ME, Güngör E, İzgi $\mathrm{H}$, İskit AT, Abbasoglu O, Ariogul S. Malnutrition in Turkish Nursing Homes: A Correlate of Short Term Mortality. J Nutr Health Aging 2013;17(4):305-309

8. Winter J, Flanagan D, McNaughton SA, Nowson C. Nutrition Screening of Older People in a Community General Practice, Using the MNA-SF. J Nutr Health Aging 2013;17(4):322-325.

9. Rubenstein LZ, Harker JO, Salvà A, Guigoz Y, Vellas B. Screening for Undernutrition in Geriatric Practice: Developing the Short-Form Mini-Nutritional Assessment (MNA-SF). J Gerontol A Biol Sci Med Sci. 2001 Jun;56(6):M366-72.

10. Kaiser MJ, Bauer JM, Ramsch C, Uter W, Guigoz Y, Cederholm T, Thomas DR, Anthony P, Charlton KE, Maggio M, Tsai AC, Grathwohl D, Vellas B, Sieber CC. MNA-International Group. Validation of the Mini Nutritional Assessment ShortForm (MNA-SF): A Practical Tool for Identification of Nutritional Status. J Nutr Health Aging. 2009 Nov;13(9):782-8.

11. Garcia-Meseguer MJ, Serrano-Urrea R. Validation of the revised mini nutritional assessment short-forms in nursing homes in Spain. J Nutr Health Aging. 2013;17(1):26-9.

12. Donini LM, Poggiogalle E, Morrone A, Scardella P, Piombo L, Neri B, Cava E, Cucinotta D, Barbagallo M, Pinto A. Agreement between Different Versions of the MNA. J Nutr Health Aging 2013;17(4):332-338

13. Huhmann MB, Perez V, Alexander DD, Thomas DR. A Self-Completed Nutrition Screening Tool for Community-Dwelling Older Adults with High Reliability: A Comparison Study. J Nutr Health Aging 2013;17(4):339-344

14. Diekmann R, Winning K, Uter W, Kaiser MJ, Sieber CC, Volkert D, Bauer JM. Screening for Malnutrition among Nursing Home Residents - A Comparative Analysis of the Mini Nutritional Assessment, the Nutritional Risk Screening, and the Malnutrition Universal Screening Tool. J Nutr Health Aging 2013;17(4):326-331

15. Bollwein J, Volkert D, Diekmann D, Kaiser MJ, Uter W, Vidal K, Sieber CC, Bauer JM. Nutritional Status According to the Mini Nutritional Assessment (MNA) and Frailty in Community Dwelling Older Persons: A Close Relationship. J Nutr Health Aging 2013;17(4):351-356

16. Stange I, Poeschl K, Stehle P, Sieber CC, Volkert D. Screening for Malnutrition in Nursing Home Residents: Comparison of Different Risk Markers and their Association to Functional Impairment. J Nutr Health Aging 2013;17(4):357-363

17. Kiesswetter E, Pohlhausen S, Uhlig K, Diekmann R, Lesser S, Heseker H, Sieber CC, Volkert D. Malnutrition Is Related to Functional Impairment in Older Adults Receiving Home Care. J Nutr Health Aging 2013;17(4):345-350

18. Muzembo BA, Nagano Y, Dumavibhat N, Ngatu NR, Matsui T, Bhatti SA, Eitoku M, Hirota R, Ishida K, Suganuma N. Ankle-Brachial Pressure Index and Mini Nutritional Assessment in Community-Dwelling Elderly People, J Nutr Health Aging 2013;17(4):370-376

19. Charlton KE, Walton K, Moon L, Smith K, McMahon AT, Ralph F, Stuckey M, Manning F, Krassie J. It Could Probably Help Someone Else but Not Me": A Feasibility Study of a Snack Programme Offered to Meals on Wheels Clients. J Nutr Health Aging 2013;17(4):364-369 